\title{
O ateliê do artista Arlindo Daibert
}

Marília Andrés Ribeiro, Universidade Federal de Minas Gerais, Belo Horizonte, MG; E-mail: <marilia.andres@gmail.com>.

André Melo Mendes, Universidade Federal de Minas Gerais; Belo Horizonte, MG; E-mail: <andremelomendes@hotmail.com>.

\section{Resumo}

Propomos desvendar o trabalho de ateliê de Arlindo Daibert, pautado pela experimentação com diferentes técnicas, e discutir o seu pensamento sobre a arte, o artista, a poesia e a literatura. Tomaremos como eixo de nossa reflexão o diálogo entre a arte e a literatura que está presente de forma marcante na obra de Daibert, tanto nas diversas releituras que o artista faz das obras de grandes autores como Lewis Caroll, Guimarães Rosa e Mário de Andrade, quanto na recriação da poesia de Murilo Mendes, que era um grande amigo de Daibert e com o qual ele mantia um diálogo intermidiático. No Caderno de escritos (1995), Daibert nos aponta a admiração de Murilo Mendes por Vermeer de Delf, artista holandês do século XVII que fez uma das obras mais marcantes sobre 0 ateliê do artista. Pretendemos discutir a relação intermidiática entre o poema de Murilo Mendes "Vermeer de Delf", publicado no livro Poesia e liberdade (1945), e a pintura de Vermeer, $O$ pintor em seu ateliê (1666), bem como a relação intramidiática entre as inúmeras releituras feitas por Daibert dessa obra antológica do artista holandês. A figura do artista no seu atelier, a partir de Vermeer, torna-se a assinatura de Daibert, um artista concentrado no processo de trabalho, no fazer artístico e no universo da arte.

Palavras-chave: Intermídia, Ateliê, Arlindo Daibert

\section{Introdução}

Propomos mergulhar no ateliê do artista Arlindo Daibert (19521993), para desvendarmos o seu trabalho de ateliê, pautado pela experimentação com diferentes técnicas e o seu pensamento sobre a arte, o artista, a poesia, a literatura e a história. 
Tomaremos como eixo de nossa reflexão o diálogo entre a arte e a literatura, que está presente de forma marcante na obra de Daibert, tanto nas diversas releituras que o artista faz das obras de grandes escritores, como Lewis Caroll, Guimarães Rosa, Mário de Andrade, quanto na recriação da poesia de Murilo Mendes (1901-1975), que era um grande amigo de Daibert e com o qual ele mantinha um diálogo intermidiático.

Focalizaremos nossa atenção no diálogo entre Arlindo Daibert, Murilo Mendes e Johannes Vermeer (1632-1675), pintor holandês que viveu em Delft, no século XVII, durante o período de florescimento do Barroco nos Países Baixos e deixou uma obra exemplar, em torno de 40 telas, mostrando cenas cotidianas da vida dos holandeses na cidade de Delft.

\title{
Murilo Mendes: o olho armado
}

No Caderno de escritos (1995) Daibert nos aponta a admiração de Murilo Mendes pelas artes visuais, seu relacionamento com os artistas modernos e sua atuação como poeta, crítico, professor e colecionador. ${ }^{1}$ Daibert salienta o encantamento de Murilo com a Holanda e a obra de Vermeer, apontando o poema de Murilo dedicado a Vermeer de Delft, publicado, em 1945, no livro Poesia liberdade.

\author{
Vermeer de Delft \\ É a manhã no copo: \\ Tempo de decifrar o mapa \\ Com seus amarelos e azuis, \\ De abrir as cortinas - o sol frio nasce \\ Nos ladrilhos silenciosos -, \\ De ler uma carta perturbadora \\ Que veio pela galera da China: \\ Até que a lição do cravo \\ Através dos seus cristais \\ Restitui a inocência (Mendes, 2014: 109).
}

Segundo Daibert, Murilo Mendes viaja à Holanda em 1952, quando entrou em contato com o universo poético de Vermeer

e

${ }^{1}$ Ver: Mendes, 1995: 109-111. 
traça uma verdadeira panorâmica dos principais temas e imagens mais recorrentes do universo pictórico do artista. Elementos como o copo, o mapa, as cortinas, a carta e o cravo são alinhados com o rigor de imagens cinematográficas em oito versos sínteses (Daibert, 1995b: 96).

$\mathrm{Na}$ sua revisão dos poemas, em 1959, Murilo Mendes acrescenta dois versos fundamentais que falam dos amarelos e azuis e dos ladrilhos silenciosos, iluminados pela luz de Delft. O poeta enfatiza a presença da luz na obra de Vermeer, a mesma luz que está presente na cidade de Delft e que unifica o "interior" e o "exterior". ${ }^{2}$ A luz é um elemento-chave na obra de Vermeer; ela entra através da janela e ilumina cada detalhe do interior com uma sutileza e uma delicadeza própria do olhar tátil do artista.

A luz ilumina o interior da casa, o mobiliário, as cortinas, os objetos, os personagens da burguesia holandesa, a família, a modelo e o trabalho cotidiano da empregada, da rendeira, do músico, do geógrafo, do astrônomo e do pintor.

Ainda segundo Daibert, "dos artistas holandeses do século XVII talvez Vermeer seja o que melhor encarna os ideais de uma pintura meditativa, silenciosa, analítica e - por que não? metafísica" (Daibert, 1995b: 97).

Daibert aponta o significado da viagem à Holanda para Murilo Mendes e seu encontro com a harmonia, o equilíbrio, a clareza e a pureza, elementos que estão presentes na obra de Vermeer e na obra de Mondrian. Esse artista, que também era holandês, representou a síntese da arte moderna ocidental, trabalhando com as cores primárias e as figuras geométricas essenciais, equilibradas pelas linhas verticais e horizontais. Para Murilo Mendes,

Vermeer conduz a Mondrian, ambos nos ajudam a interpretar o gênio de planificação do homem holandês, rompendo um isolamento imposto pela natureza. $\mathrm{O}$ rigor da construção em Mondrian faz dele um continuador de

2 Ver: Mendes, 1994b: 1085-86. 
Vermeer, o último representante de uma longa linha de artistas criadores (Mendes, 1994a: 97).

Tanto Vermeer quanto Mondrian são artistas construtores, representam uma perspectiva apolínea da cultura ocidental que está presente também na poética de Murilo Mendes.

Segundo Daibert:

Construir, para o poeta, significa ordenar o caos, aproximar-se da perfeição e, mais importante, resgatar uma harmonia primitiva que coloca o artista em contato direto com a Divindade. O conceito dessa harmonia primeira perpassará sempre as ideias estéticas de Murilo, interligando numa mesma cadeia obras, artistas, lugares e épocas diferentes, todos irmanados por essa perfeição arquetípica (Daibert, 1995a: 97).

Murilo Mendes era um escritor católico, que buscava expressar - através da poesia, da prosa e dos aforismos - o sentimento religioso, filosófico e estético da modernidade. Os aforismos reunidos no livro Os discípulos de Emaús explicitam a sua posição religiosa e filosófica, bem como o seu conhecimento da arte moderna ocidental. No aforismo "há uma espécie de meditação plástica tão intensa como uma meditação filosófica" (Mendes, 1994c: 848). O poeta enfatiza a atitude meditativa, concentrada, silenciosa, tanto do artista quanto do filósofo, aproximando os dois profissionais por meio do trabalho criativo. Murilo dialoga com o pensamento artístico contemporâneo, na linhagem conceitual de Duchamp, quando ele nos diz, por meio de outro aforismo, que "um quadro é sem dúvida uma operação manual - mas é o resultado de inúmeras antecedentes operações visuais e mentais" (Mendes, 1994c: 848). Para Duchamp e seus seguidores, que são os artistas conceituais contemporâneos, a arte é, antes de tudo, conceitos, propostas e ideias.

A ponte entre o pensamento moderno e contemporâneo de Murilo Mendes nos leva a desvendar a obra e o pensamento de Arlindo Daibert, que aparece nos seus escritos, cadernos de bordo, cadernos de desenhos, nas pinturas, nos recortes e objetos, em que o artista reverencia o poeta Murilo Mendes e apropria-se do pintor Johannes Vermeer. 


\section{Arlindo Daibert: o olho crítico}

Daibert, na sequencia de Murilo, escolhe Vermeer como seu artista predileto e estabelece uma relação intramidiática com a obra de Vermeer a partir da pintura $O$ pintor em seu ateliê ou $A$ alegoria da pintura, realizando inúmeras releituras e recriações dessa obra antológica do artista holandês. ${ }^{3}$ A pintura de Vermeer é um óleo sobre tela, realizada em 1666, no contexto do barroco holandês, um barroco intimista, construído através da pintura de cavalete, encomendada pelos comerciantes da burguesia holandesa.

Nesse contexto, é interessante lembrar que Johannes Vermeer era filho de um comerciante de objetos e de obras de arte; ele também comercializava suas obras que eram feitas sobre encomenda. A encomenda mais instigante é a obra-prima de Vermeer, Moça com brinco de pérolas (1666), um retrato de Griet, a empregada da família, realizado com afeto e maestria, registrando o instante em que a modelo, iluminada no fundo negro, olha com ternura e inocência para o artista. ${ }^{4} \mathrm{~A}$ pintura nos mostra a relação afetuosa, terna e apaixonada, entre Vermeer e Griet. Entendemos que Moça com brinco de pérolas propicia um diálogo afetivo não só com o artista, mas também com o espectador. O olhar que ela dirige ao pintor é de muito afeto e sensualidade e nós nos deliciamos com esse olhar porque nós também estamos recebendo esse olhar como espectador. Essa obra é considerada pela crítica de arte como a "Mona Lisa holandesa", o retrato mais belo do barroco holandês.

\footnotetext{
${ }^{3}$ A relação intramidiática se dá entre obras de uma mesma mídia, de uma mesma área. Para alguns autores trata-se de uma paráfrase e para outros é um comentário, uma releitura ou uma livre interpretação de uma obra anterior.

${ }^{4}$ Ver a relação afetiva entre Vermeer e Griet no romance de Tracy Chevalier, A moça com Brinco de Pérolas, publicado pela Bertrand Brasil, Rio de Janeiro, 2007, e também apresentada no filme homônimo de Peter Webber, realizado em 2003.
} 
Voltemos ao pintor no seu ateliê, onde o artista Vermeer abre a cortina de seu estúdio e convida o espectador para assentar numa cadeira e contemplar o artista no seu ambiente de trabalho, pintando a sua musa. ${ }^{5}$ Ela aparece ao fundo, iluminada pela luz, segurando um livro e um instrumento musical. O artista está de costas, assentado num banco e iniciando a pintura de cavalete. O que importa naquele momento é registrar o processo do trabalho do artista, a relação que se estabelece entre o artista e a modelo e também entre o artista e o espectador, que se coloca como um voyeur da cena. A questão do voyeur é acentuada nesse quadro, porque nós somos uma pessoa dentro do quadro, alguém diferente do pintor. O espectador mudou de posição, nós estamos atrás do artista e ele está de costas para nós. A nossa posição é daquele que está sendo convidado para entrar no quadro.

Perguntamos por que Arlindo Daibert escolheu o pintor Vermeer, aquele que está de costas para o espectador, concentrado no seu fazer artístico, como uma referência fundamental de suas releituras e recriações poéticas?

O interesse de Daibert pela releitura da obra de grandes artistas como Ingres, Velásquez, Manet e Picasso aparece em 1979, na série Manière de prononcer, cuja proposta era discutir a história da arte ocidental através de experimentações com desenhos e colagens. A partir dessas releituras surge a série Retrato do artista, que apresenta o artista em seu ateliê a partir do recorte da figura de Vermeer, em diálogo com várias

${ }^{5}$ Retratar $\mathrm{O}$ ateliê é uma prática recorrente nas artes plásticas desde o século $\mathrm{XVI}$, quando Vasari descreve o ateliê como complemento dos caracteres dos artistas no livro As vidas dos mais excelentes arquitetos, pintores e escultores. Nos séculos seguintes, temos como exemplos dessa prática as obras-primas de Rembrandt (Retrato de um pintor em seu studio); Velazquez (As meninas), Goya ( $A$ família de Carlos $V$ ), Courbet ( $O$ ateliê do artista), entre outros. Ver: Planas, 2001. 
experimentações artísticas pautadas pelo desenho e pela colagem ${ }^{6}$. A série Retrato do artista

discute a questão da citação na obra de arte, do desenho como expressão artística, das relações do artista com os modelos estéticos e com sua própria obra, bem como a própria história da arte. A figura do artista funciona como um narrador que introduz a partir de sua mão uma imagem e desencadeia o desenho (Melo \& Ribeiro \& Silva, 2000: 30).

O próprio Daibert nos esclarece essa questão no depoimento que fez sobre essa série, escrita em 1980 e publicada no Caderno de escritos. De acordo com suas palavras:

Durante todos estes anos atuando como desenhista, duas questões básicas têm me interessado como matéria de investigação: o desenho enquanto linguagem e as relações do artista com os "modelos estéticos" e com a sua própria obra (Melo \& Ribeiro \& Silva, 2000: $67)$.

A questão da posição política do artista surge do fazer artístico e da reflexão sobre a arte. Arlindo Daibert se situa como artista latino-americano e questiona os modelos hegemônicos impostos pela cultura europeia ocidental: "A partir de 1978 a minha matéria de trabalho passou a ser a pintura ocidental ou os modelos que sempre nos foram apresentados como legítimos e dignos de serem imitados e seguidos(Melo \& Ribeiro \& Silva, 2000: 67).

Nesse sentido, o artista se apropria do ateliê de Vermeer para refletir sobre o processo de fazer arte e a situação do artista no contexto histórico.

De acordo com Daibert:

O atelier de Jan Vermeer se mostrou um ótimo objeto de estudo. O quadro, de certa forma, fala do próprio ato de pintar: num primeiro plano o pintor é visto ao cavalete, trabalhando numa tela ainda inacabada; à sua frente, 0 modelo vestido com os atributos da musa de História. Difícil encontrar algo mais sintético: as relações entre

${ }^{6}$ Ver apresentação de Arlindo Daibert em: Ribeiro, Marilia Andrés. Introdução às artes visuais em Minas Gerais. Belo Horizonte, C/Arte, 2013: p. 81-82 . 
pintor/obra/modelo e, num segundo nível, a insinuação do pintor em confronto com o processo histórico (Melo \& Ribeiro \& Silva, 2000: 67).

No caso de Daibert, a figura de Vermeer funciona como um narrador, um dispositivo que leva o artista a pensar sobre 0 trabalho do artista, o fazer artístico e a inserção do artista no seu contexto histórico.

Hoje, do quadro de Vermeer sobrou apenas a figurinha do artista, que acabou sendo uma espécie de narrador dentro do trabalho que venho desenvolvendo a mais de um ano Retrato do artista, mostrado em parte na XV Bienal de São Paulo (Melo \& Ribeiro \& Silva, 2000: 67$68)$.

$\mathrm{Na}$ sequencia dos Primeiros cadernos de desenho, Daibert apropria da pintura Descanso do modelo, de José de Almeida Junior, artista brasileiro que teve uma grande importância no século XIX, tendo sido premiado com a bolsa de estudos em Paris durante o reinado de D. Pedro II. A apropriação de Almeida Junior por Daibert coloca questões de influência, de técnica e de história da arte. O pintor holandês se posiciona de frente para o brasileiro - um se espelha no outro, mas o holandês, agora é um desenho, enquanto o brasileiro é a fotografia de uma pintura. Ao contrário de Vermeer, em que o artista se coloca de costas, Almeida Junior é representado de frente, semelhante à postura de Velásquez pintando Las Meninas. Mas Almeida Junior está mostrando o não trabalho, o descanso do artista e do modelo. O modelo já não está no seu lugar apropriado, mas aparece subvertendo essa relação, agindo e praticando uma outra arte; o modelo é a artista que toca piano para o pintor.

O crítico Frederico Morais, que acompanhou a trajetória de Arlindo Daibert desde os anos de 1970, considera o artista como um dos maiores representantes do Desenho Brasileiro. Salienta que "a proposição básica (do artista) é a assimilação do desenho como método de raciocínio e instrumento de análise do próprio processo de criação" e completa o texto dizendo que "ao dar ao seu desenho a força de um comentário sobre a pintura (dos grandes mestres), Arlindo Daibert, mais 
uma vez, está afirmando a autonomia do desenho"7 e discutindo a sua importância dentro do sistema de arte.

Em 1980, com os trabalhos da série Retrato do artista, Daibert recebe vários prêmios em Salões, Bienais e realiza algumas exposições individuais, entre elas, $O$ retrato do artista, realizada em 1982 na Galeria Projecta, em São Paulo. ${ }^{8}$ Portanto, essa série legitima e torna visível a obra do artista no circuito de arte brasileiro e internacional. ${ }^{9}$

Nos anos de 1980, Daibert continua usando a marca do artista Vermeer nos seus recortes e pinturas objetos. Naquele momento ele estabelece um diálogo com o movimento de resgate da pintura, acompanhando o surgimento do grupo neoexpressionista, na Alemanha, e da Geração 80, no Brasil. As pinturas e objetos dessa época revelam uma outra faceta do artista, que redescobre o prazer lúdico de pintar, recortar, costurar, experimentando outros materiais e técnicas.

Perguntamos, onde se situa o espectador na obra de Arlindo Daibert? Seria aquele que está sendo convidado a contemplar passivamente a obra do artista como ele se apresenta na pintura de Veermer?

É ainda Daibert que nos responde, enfatizando a obra enquanto provocação do artista que deveria produzir uma postura ao mesmo tempo sensível e crítica do espectador:

7 Morais, Frederico. Arlindo Daibert: lição de desenho e história da arte. O Globo, Rio de Janeiro, 6 jun. 1980. Apud Guimarães, 2011: p. 28-31.

${ }^{8}$ Ver Cronologia de Arlindo Daibert em Guimarães, 2011: 169-174.

9 Prêmio de Viagem ao estrangeiro do III Salão Nacional de Artes Plásticas do Rio de Janeiro e o Grande Prêmio da II Bienal IberoAmericana do México. No ano seguinte, recebe o Prêmio de Aquisição da IV Bienal de Artes Gráficas de Maldonado, no Uruguai, com trabalhos dessa mesma série e realiza a sua segunda viagem à Europa, onde apresenta a exposição individual Arlindo DaibertDesenhos, na Casa do Brasil, em Roma. 
Acho que o espectador deve ter o máximo de autoviolência para perceber a obra. Eu exijo o máximo do espectador. Quero que a pessoa se esforce. Ou, então, vem despreocupada e percebe a obra. Nesse caso agente nota que existe um ponto natural de comunicação (Melo \& Ribeiro \& Silva, 2000: 14).

Em sua reflexão sobre o trabalho do artista, Daibert volta a falar do comprometimento do artista com o seu trabalho, a sua pesquisa e de sua contribuição para o conhecimento e o saber artístico. Segundo o artista: "A arte é uma forma de investigação, de conhecimento, é um acréscimo ao patrimônio cultural. A arte tem de estar comprometida também com a inteligência. Ela deve exigir do espectador tanto esforço quanto exigiu do artista" (Daibert, 1995a: 158).

\section{Conclusão}

Ao contrário de Murilo Mendes, que fala da obra de Vermeer, da cidade de Delft e da viagem à Holanda como um poeta apaixonado, Arlindo Daibert nos apresenta o ateliê de Vermeer como um tema para a reflexão crítica sobre a sobrevivência da arte e do artista no contexto atual do mundo contemporâneo. Daibert também nos apresenta imagens do seu ateliê mental quando escreve textos em que explica e reflete sobre seu processo de criação. Em Cadernos de escritos, Castañon reúne os textos de Daibert e assim nos proporciona uma visão mais completa do artista, como se abrisse a cortina do seu ateliê para contemplarmos seu ambiente de trabalho intelectual. A partir dessa visada nos é permitido entender como o processo de criação de Daibert é baseado num pensamento racional e estruturado, em que faz escolhas baseadas em argumentos racionais, sem deixar de lado a emoção lúdica e poética de fazer arte.

Imagens 


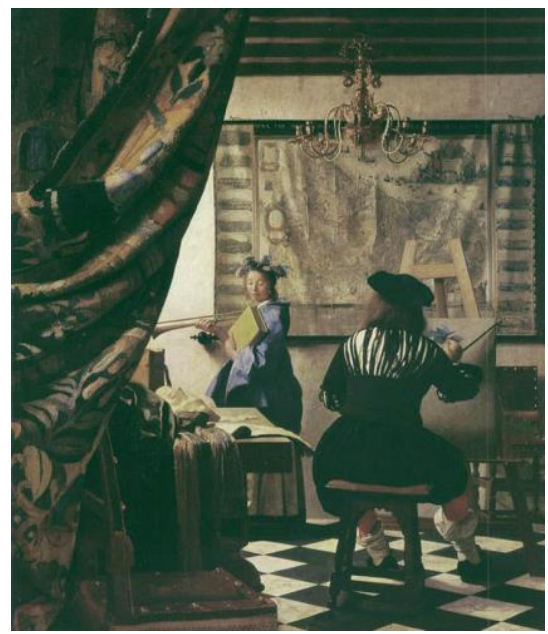

Fig. 1: O pintor em seu ateliê, óleo s/tela, 1666. Johannes Vermeer.

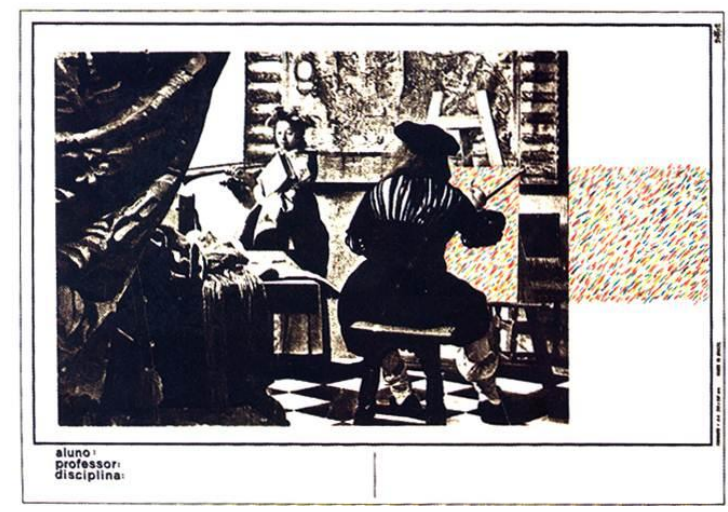

Fig. 2: Da Série Primeiro caderno de desenho, técnica mista sobre papel, 1979. Arlindo Daibert.

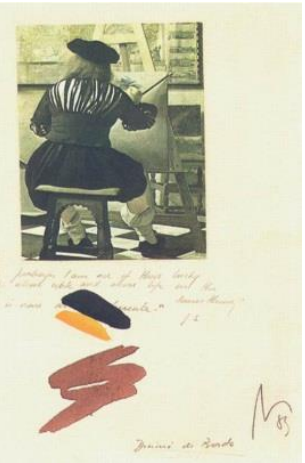

Fig. 3: Diário de Bordo, técnica mista, 1983. Arlindo Daibert.

\section{Referências}

Daibert, A. (1995a). O trabalho do artista. In: .Caderno de escritos. Rio de Janeiro, Sette Letras.

Daibert, A. (1995b). Vermeer de Delft. In: . Caderno de escritos. (Organização de Júlio Castañon Guimarães). Rio de Janeiro, Sette Letras, 1995. p. 96. 
Guimarães, J. C. (2011). (Org.). Arlindo Daibert: fortuna crítica. Juiz de Fora, UFJF/MAMM; Rio de Janeiro, Casa Rui Barbosa.

Melo, J. \& Ribeiro, M. A. \& Silva, F. P. da (2000). Arlindo Daibert depoimento. Belo Horizonte: C/Arte, (Circuito Atelier).

Mendes, M. (1994a). A Holanda. In: Prosa/Carta Geográfica.

Poesia Completa e Prosa. Rio de Janeiro: Nova Aguilar.

Mendes, M. (1994b). Delft. In: Prosa/Carta geográfica. Poesia Completa e Prosa. Rio de Janeiro: Nova Aguilar. p. 1085-86.

Mendes, M. (1994c). São Lucas, Cap. XXIV. In: Prosa/Os discípulos de Emaús. Poesia Completa e Prosa. Rio de Janeiro: Nova Aguilar. p. 848.

Mendes, M. (1995). O olho armado. In: Daibert, Arlindo. Caderno de escritos. (Organização de Júlio Castañon Guimarães). Rio de Janeiro, Sette Letras. p. 109-111.

Mendes, M. (2014). Vermeer de Delft. In: Antolologia poética. Murilo Mendes. São Paulo: Cosac Naify.

Planas, Claustre Rafart (2001). Las meninas de Picasso. Barcelona: Editorial Meteora.

Ribeiro, Marília Andrés (2013). Introdução às artes visuais de Minas Gerais.Belo Horizonte, C/Arte. 